\title{
Norcantharidin inhibits viability and induces cell cycle arrest and apoptosis in osteosarcoma
}

\author{
YINGCHUN ZHU, YUNFENG MI, ZHEYANG WANG, XUEWEN JIA and ZHANPING JIN \\ Department of Orthopedics, Ningbo First Hospital, Ningbo, Zhejiang 315000, P.R. China
}

Received January 2, 2018; Accepted August 22, 2018

DOI: $10.3892 / \mathrm{ol} .2018 .9615$

\begin{abstract}
Osteosarcoma is the most frequent malignant bone tumor in children and adolescents. Norcantharidin (NCTD) is a purified component from blister beetles and has been identified to exert antitumor effects in a variety of cancer types. However, the antitumor effect of NCTD in osteosarcoma remains to be elucidated. In the current study, it was first demonstrated that NCTD inhibited proliferation and induced G2/M-phase arrest and cell apoptosis in human osteosarcoma cells. Furthermore, NCTD significantly decreased the phosphorylation of Akt and the mammalian target of rapamycin in human osteosarcoma cells. These results suggest that NCTD is a promising candidate for the treatment of osteosarcoma patients in the future.
\end{abstract}

\section{Introduction}

Osteosarcoma, the most common primary malignant bone tumor in children and adolescents, arises from cells of mesenchymal osteoblast origin $(1,2)$. Despite considerable advances in surgery and multiagent chemotherapy, the cure rate has not significantly increased over the past 20 years $(3,4)$. Therefore, the development of novel treatments and drugs for osteosarcoma treatment is urgently required.

Norcantharidin (NCTD), which is a purified component from blister beetles, is well-known for its antioxidant, antitumor and antimetastatic functions. Previous studies have reported that NCTD exhibits potential antitumor activity in a variety of cancer types, including oral cancer (5), colorectal adenocarcinoma $(6,7)$ and urinary bladder carcinoma (8). However, to the best of our knowledge, the antitumor effect of NCTD in osteosarcoma and the underlying molecular mechanisms of this effect have never been investigated.

Correspondence to: Mrs Zhanping Jin, Department of Orthopedics, Ningbo First Hospital, 59 Liuting Street, Ningbo, Zhejiang 315000, P.R. China

E-mail: 13819842890@163.com

Key words: apoptosis, norcantharidin, osteosarcoma, cell cycle, Akt/mammalian target of rapamycin
In the current study, it was demonstrated that NCTD inhibits proliferation and induces G2/M-phase arrest and cell apoptosis in human osteosarcoma cells. Furthermore, the possible mechanisms of NCTD action in Akt/mammalian target of rapamycin (mTOR) signaling pathways are discussed. Collectively, the current data suggest that NCTD may be an anticancer agent for the treatment of osteosarcoma.

\section{Materials and methods}

Cells and cell culture. The human osteosarcoma cell lines 143B and SJSA were purchased from American Type Culture Collection (Manassas, VA, USA) and cultured in high-glucose Dulbecco's modified Eagle's medium (HyClone; GE Healthcare, Logan, UT, USA) supplemented with $10 \%$ fetal bovine serum (HyClone; GE Healthcare), $100 \mathrm{U} / \mathrm{ml}$ penicillin and $100 \mathrm{mg} / \mathrm{ml}$ streptomycin (Thermo Fisher Scientific, Inc., Waltham, MA, USA) in a humidified incubator at $37^{\circ} \mathrm{C}$ in $5 \% \mathrm{CO}_{2}$.

Materials and chemicals. NCTD (Fig. 1A) was obtained from the National Institutes for Food and Drug Control (Shandong, China), dissolved in dimethyl sulfoxide (DMSO) as an $80 \mathrm{mmol} / 1$ stock solution and stored in the dark at $-20^{\circ} \mathrm{C}$. Antibodies against cleaved-caspase-3 (cat. no. 9661), cleaved-poly (ADP-ribose) polymerase (cleaved-PARP; cat. no. 5625), Akt (cat. no. 4685), mTOR (cat. no. 2983), phosphorylated (p)-Akt (cat. no. 4060), p-mTOR (cat. no. 5536) and GAPDH (cat. no. 5174) and an anti-rabbit IgG horseradish peroxidase (HRP)-linked antibody (cat. no. 7074) were purchased from Cell Signaling Technology, Inc. (Danvers, MA, USA).

Cell viability assay. Cells of the 143B and SJSA human osteosarcoma cell lines were seeded in 96-well plates (2,000 cells/well). After growing for $24 \mathrm{~h}$ in the incubator, the medium was aspirated, and the cells were then treated with $200 \mu \mathrm{l}$ of complete medium containing various concentrations of $\operatorname{NCTD}(0,10,20,40,80$ and $160 \mu \mathrm{M})$. NCTD was dissolved in DMSO, and the concentration of DMSO was kept at $<0.05 \%$ in all wells. After $24 / 48$ h of incubation, Cell Counting Kit-8 (CCK8) solution was added to each well at a final concentration of $5 \mathrm{mg} / \mathrm{ml}$. Following incubation for an additional $4 \mathrm{~h}$ at $37^{\circ} \mathrm{C}$, the supernatants were removed, and $100 \mathrm{ml} \mathrm{DMSO}$ was added to each well. The absorption was measured at $550 \mathrm{~nm}$ 
by a microplate spectrophotometer. Three independent experiments were carried out in triplicate. The cell growth inhibition at each NCTD concentration was measured, and the $\mathrm{IC}_{50}$ values were calculated using the SPSS 19.0 statistical software package (IBM Corp., Armonk, NY, USA).

Cell cycle analysis by flow cytometry. Cells of the 143B and SJSA human osteosarcoma cell lines were cultured in 6-well plates at a density of $5 \times 10^{5} / \mathrm{ml}$ and treated with NCTD at the indicated concentration for $12 \mathrm{~h}$. After treatment, the cells were harvested, washed three times with phosphate-buffered saline (PBS) and fixed with cold $70 \%$ ethyl alcohol at $4^{\circ} \mathrm{C}$ overnight. The cells were then stained with PI/RNase staining buffer (BD Biosciences, Franklin Lakes, NJ, USA) for $15 \mathrm{~min}$ at room temperature and analyzed by an Accuri C6 flow cytometer (BD Biosciences). In addition, the data were analyzed using ModFit LT v3.1 software (FACSCalibur; BD Biosciences).

Morphological characteristics of apoptosis. A Hoechst assay was performed to evaluate the morphological characteristics of apoptotic cells after NCTD treatment. In brief, 143B human osteosarcoma cells were seeded in 6-well plates at a density of $5 \times 10^{5} / \mathrm{ml}$ and exposed to vehicle or NCTD at the indicated concentration for $12 \mathrm{~h}$. Then, the cells were fixed with $4 \%$ paraformaldehyde for $15 \mathrm{~min}$ at room temperature and washed three times with PBS. Next, the cells were permeabilized with $0.1 \%$ Triton-X-100 and stained with Hoechst 33258 (Beyotime Institute of Biotechnology, Shanghai, China) for $10 \mathrm{~min}$ at room temperature in the dark. The cells were observed under a fluorescence microscope.

Flow cytometric analysis of apoptosis. The Annexin V-FITC/propidium iodide (PI) double staining assay (Beyotime Institute of Biotechnology) was used to detect cell apoptosis according to the manufacturer's protocol. Briefly, 143B human osteosarcoma cells were seeded in 6-well plates at a density of $5 \times 10^{5} / \mathrm{ml}$ and exposed to vehicle or NCTD at the indicated concentration for $24 \mathrm{~h}$. Then, the cells were harvested, washed three times with cold PBS and stained with Annexin V-FITC and PI for 15 min in the dark at room temperature. In addition, the data were analyzed using Accuri C6 software (BD Biosciences).

Western blot assay. Cells were washed three times with cold PBS solution, and protein was extracted using RIPA Lysis Buffer (Beyotime Institute of Biotechnology) containing protease and phosphatase inhibitors (Beyotime Institute of Biotechnology). After quantification with the Standard BCA Protein Assay kit (Beyotime Institute of Biotechnology), equal amounts of protein $(40 \mu \mathrm{g})$ were boiled, electrophoretically separated on 10 or $15 \%$ polyacrylamide gels at $80-120 \mathrm{~V}$ and transferred onto polyvinylidene difluoride membranes (EMD Millipore, Billerica, MA, USA) at 80-120 V for 1-2 h. Then, the membranes were blocked with $5 \%$ bovine serum albumin (Sigma-Aldrich; Merck KGaA, Darmstadt, Germany) for $60 \mathrm{~min}$ at room temperature and incubated overnight at $4^{\circ} \mathrm{C}$ with 1:1,000 dilutions of the primary antibodies. After incubation, the membranes were washed three times with PBS containing $0.1 \%$ Tween-20 and then probed with an HRP-conjugated secondary antibody $(1: 5,000)$ for $1 \mathrm{~h}$ at room temperature. Antibody binding was visualized with enhanced chemiluminescence (ECL) using an ECL substrate (EMD Millipore).

Statistical analysis. All data analyses were performed using SPSS software (version 18.0; SPSS, Inc., Chicago, IL, USA). The data are presented as the mean \pm standard deviation. The statistical differences were calculated by one-way analysis of variance with Dunnett's test or unpaired Student's t-test. $\mathrm{P}<0.05$ was considered to indicate a statistically significant difference.

\section{Results}

NCTD inhibits cell viability in $143 B$ and SJSA human osteosarcoma cells in a time- and dose-dependent manner. To explore the cytotoxicity of NCTD in human osteosarcoma cells, the growth of $143 \mathrm{~B}$ and SJSA cells treated with NCTD was assessed by CCK 8 assay. The cells were treated with various concentrations of NCTD for 24 and $48 \mathrm{~h}$, followed by performance of the CCK8 assay. As indicated in Fig. 1B and C, NCTD significantly decreased osteosarcoma cell viability, compared with the control $(\mathrm{P}<0.05)$. The $\mathrm{IC}_{50}$ values for 143B and SJSA were 28.75 and $36.56 \mu \mathrm{M}$, respectively, after $24 \mathrm{~h}$ of NCTD treatment. After $48 \mathrm{~h}$ of NCTD treatment, the $\mathrm{IC}_{50}$ values for $143 \mathrm{~B}$ and SJSA were 13.98 and $18.08 \mu \mathrm{M}$, respectively. These results demonstrated that NCTD inhibits the proliferation of osteosarcoma cells in a dose- and time-dependent manner.

NCTD induces cell cycle arrest in $143 B$ and SJSA human osteosarcoma cells. To further explore the mechanism of the antiproliferative effect of NCTD in osteosarcoma cells, cell cycle distribution was analyzed by flow cytometry after NCTD treatment. As indicated in Fig. 2, the percentage of osteosarcoma cells in G2/M phase was increased after $24 \mathrm{~h}$ treatment with increasing concentrations of NCTD. A corresponding decrease was noted in the percentage of cells in $G_{1}$ phase. These data indicate that NCTD induces G2/M cell cycle arrest in 143B and SJSA human osteosarcoma cells.

NCTD induces cell apoptosis in human osteosarcoma cells. Next, NCTD-induced apoptotic cell death in osteosarcoma cells was explored. Hoechst staining was used to evaluate NCTD treatment-altered cell morphology. As indicated in Fig. 3A, cell shrinkage, nuclear fragmentation and chromatin condensation were observed after treatment with $10 \mu \mathrm{M}$ NCTD for $24 \mathrm{~h}$. To further quantify apoptosis, Annexin V-FITC/PI double staining was used. The results demonstrated that treatment with NCTD significantly increased the percentage of both early and late apoptotic cells, compared with the control $(\mathrm{P}<0.05$; Fig. $3 \mathrm{~B}$ and $\mathrm{C})$. After treatment with $40 \mu \mathrm{M}$ NCTD for $24 \mathrm{~h}, 44.6 \%$ of cells were dead $(11.9 \%$ of cells were early apoptotic, $19.5 \%$ of cells were late apoptotic and $13.2 \%$ of cells were necrotic). In addition, the western blot assay indicated that NCTD notably increased the activation of cleaved PARP and cleaved caspase-3, compared with the control (Fig. 3D). These data indicated that NCTD induced dose-dependent cell apoptosis in osteosarcoma cells. 


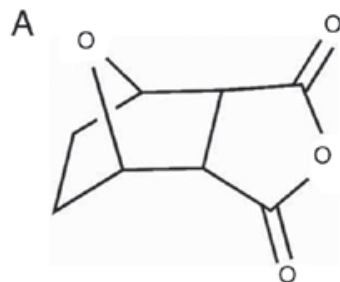

(NCTD, $\mathrm{C}_{8} \mathrm{H}_{8} \mathrm{O}_{4}, \mathrm{MW} 168.12$ )
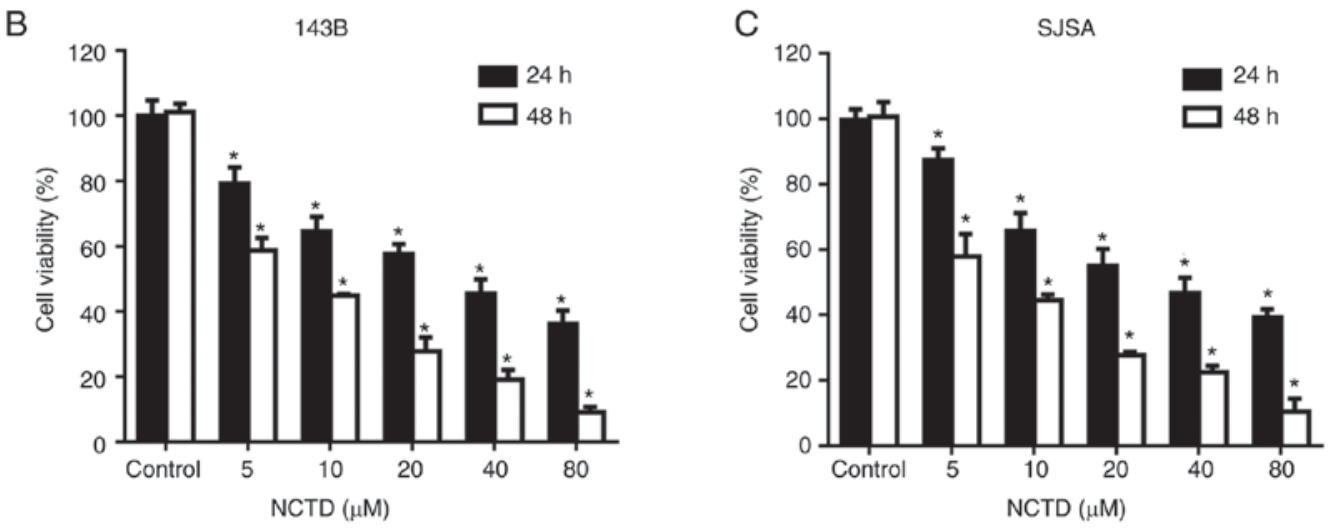

Figure 1. NCTD inhibits cell viability in osteosarcoma cells. Human osteosarcoma cell lines 143B and SJSA were treated with increasing concentrations of NCTD for 24 or $48 \mathrm{~h}$ and cell viability was measured by the CCK8 assay. (A) Chemical structure of NCTD. (B) 143B cells were treated with the indicated doses of NCTD for 24 or $48 \mathrm{~h}$. (C) SJSA cells were treated with the indicated doses of NCTD for 24 or $48 \mathrm{~h}$. Each experiment was repeated in triplicate. "P $<0.05$ vs. control. NCTD, norcantharidin.

A Control
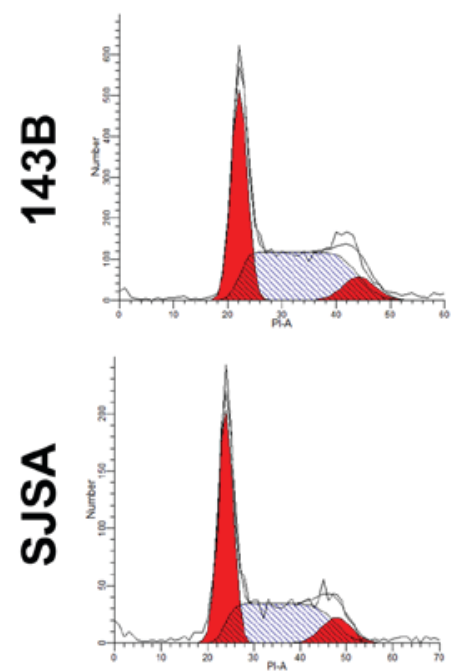

NCTD $(10 \mu \mathrm{M})$
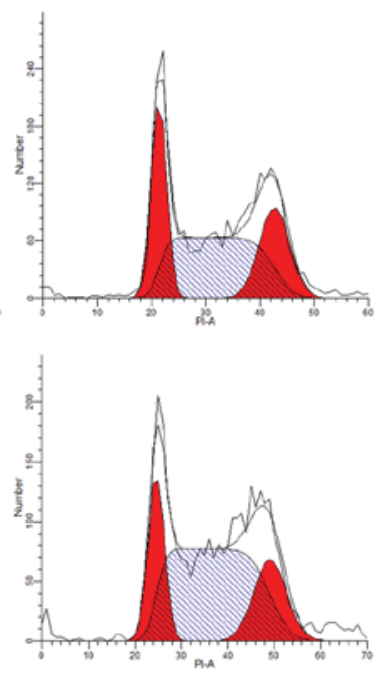

143B

B
NCTD $(20 \mu \mathrm{M})$
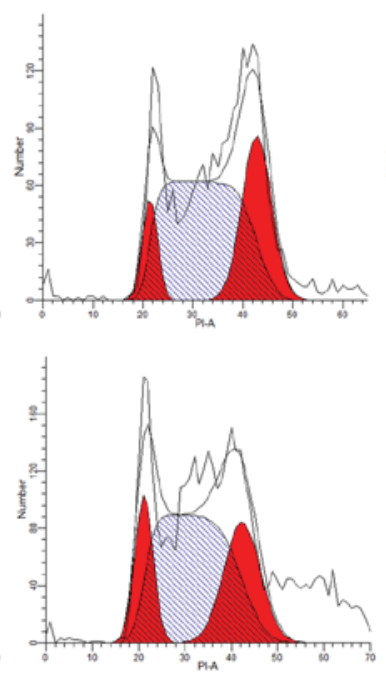

NCTD $(40 \mu M)$
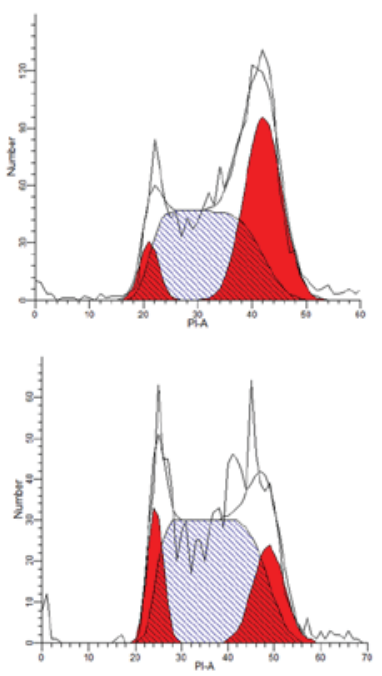

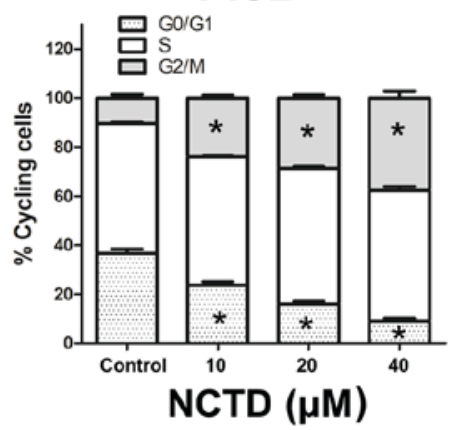

SJSA

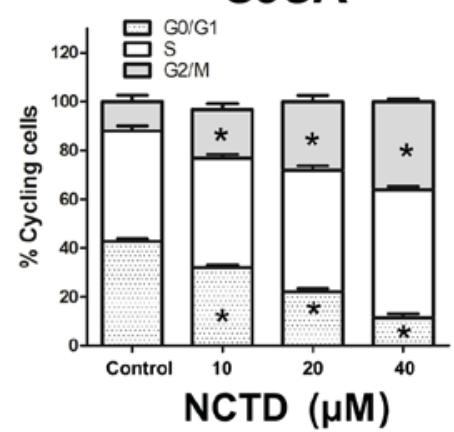

Figure 2. NCTD induces osteosarcoma cell cycle arrest. (A) Human osteosarcoma cell lines 143B and SJSA were treated with NCTD $(0,10,20$, and $40 \mu \mathrm{M})$ for $24 \mathrm{~h}$. Cells were collected fixed, stained with PI and assessed by flow cytometry. (B) Cell cycle distribution is presented as the mean \pm standard deviation of three independent experiments. "P $<0.05$ vs. control. NCTD, norcantharidin. 
A

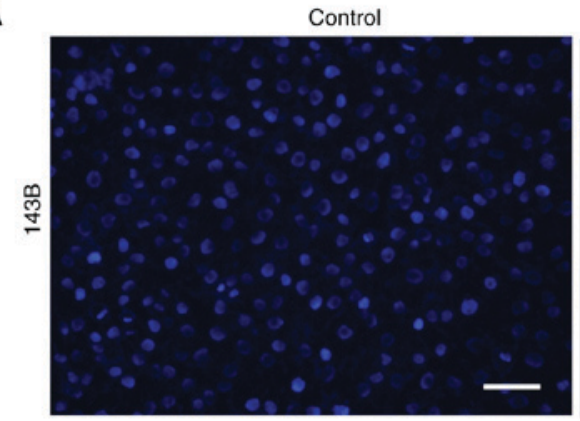

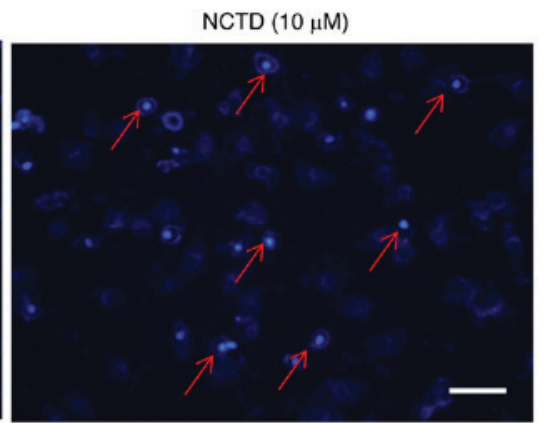

NCTD $(20 \mu \mathrm{M})$

B

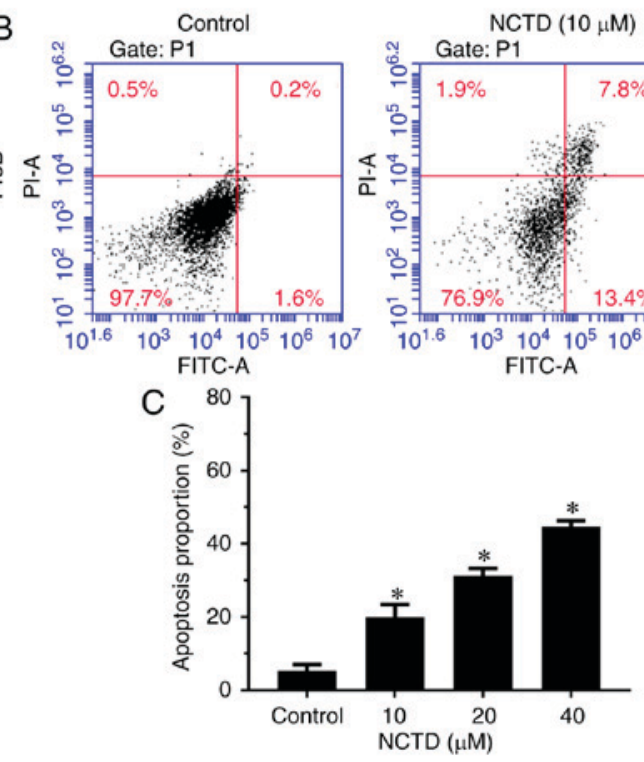

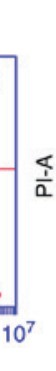
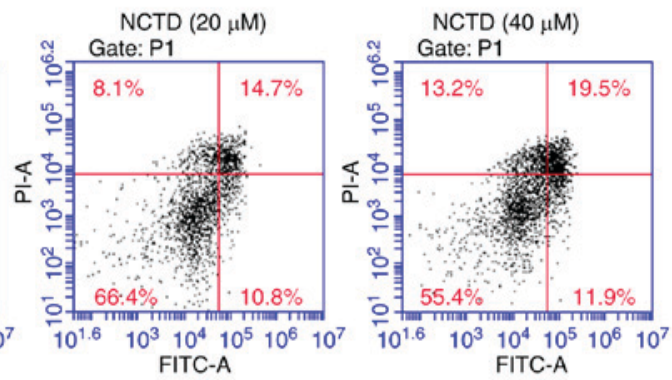

D
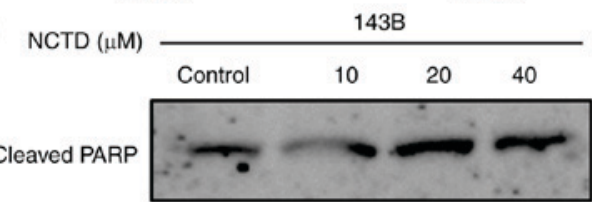

Cleaved caspase-3

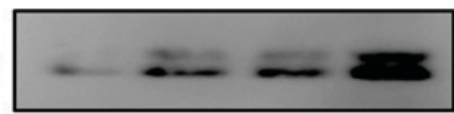

GAPDH

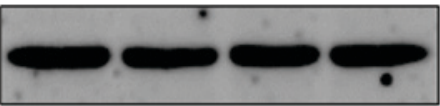

Figure 3. NCTD induces cell apoptosis in 143B human osteosarcoma cells. (A) Cells of the 143B cell line were treated with DMSO or with $10 \mu \mathrm{M} \mathrm{NCTD} \mathrm{for} 12 \mathrm{~h}$, and the cell morphology was observed under a fluorescence microscope (scale bar=50 $\mu \mathrm{m}$ ). (B) Cells were treated with DMSO or with increasing concentrations of NCTD for $24 \mathrm{~h}$ and then stained with Annexin V-FITC/PI and analyzed by flow cytometry. (C) The percentage of apoptotic cells is presented as the mean \pm standard deviation of three independent experiments. "P $<0.05$ vs. control. (D) After treatment with DMSO or with increasing concentrations of NCTD for $24 \mathrm{~h}$, the effect of NCTD on the activation of cleaved PARP and cleaved caspase-3 was detected by western blotting. NCTD, norcantharidin; PARP, poly (ADP-ribose) polymerase.

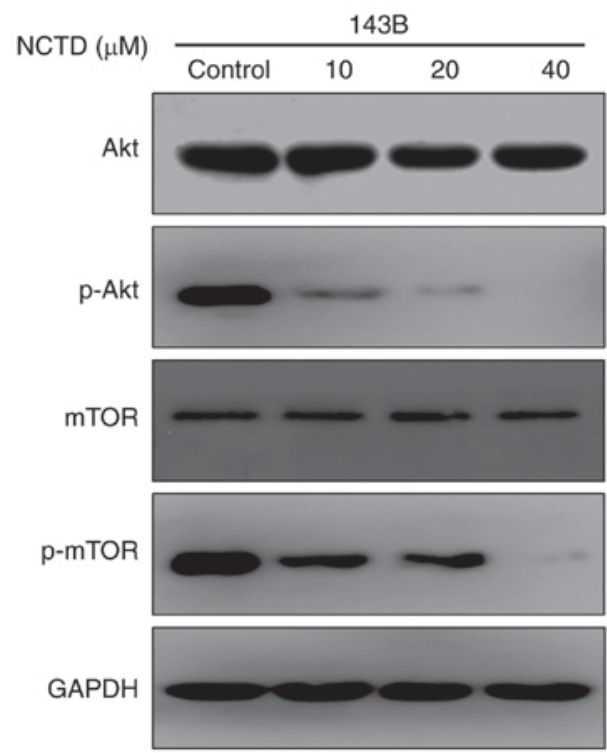

Figure 4. Effect of NCTD on the Akt/mTOR signaling pathway in human osteosarcoma cells. Cells of the 143B cell line were treated with DMSO or with increasing concentrations of NCTD for $24 \mathrm{~h}$. The change in Akt and mTOR expression was detected by western blotting. NCTD, norcantharidin; mTOR, mammalian target of rapamycin.
NCTD blocks the Akt/mTOR signaling pathway in human osteosarcoma cells. To further investigate the mechanisms underlying the antitumor activity of NCTD, a western blot assay was used to detect the effect of NCTD on the Akt/mTOR signaling pathway. As indicated in Fig. 4, NCTD markedly decreased the phosphorylation of Akt and mTOR in 143B cells. Previous studies have demonstrated that the Akt $/ \mathrm{mTOR}$ signaling pathway serves a key role in regulating cell growth and apoptosis (9). These results demonstrated that NCTD blocks the Akt/mTOR signaling pathway, an action that may be associated with the effect of NCTD on cell growth and apoptosis.

\section{Discussion}

Growing evidence suggests that traditional Chinese medicines contain anticancer ingredients $(10,11)$. NCTD, the demethylated form of cantharidin, has exhibited anticancer potential in multiple cancer cell types $(8,12,13)$. However, to the best of our knowledge, the ability of NCTD to suppress the growth of human osteosarcoma cells and the possible underlying mechanisms have never been investigated. In the present study, the antitumor effects of NCTD in osteosarcoma were investigated. 


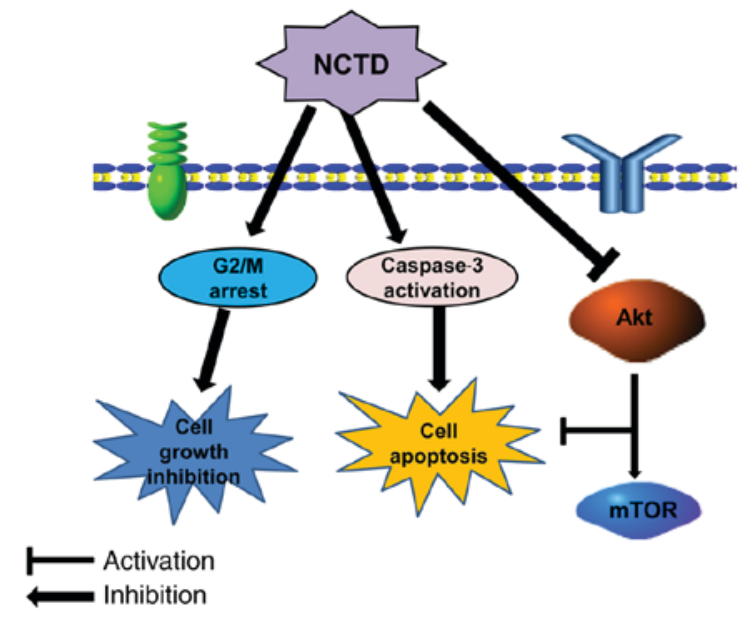

Figure 5. Proposed mechanism of NCTD-induced cell cycle arrest and apoptosis in osteosarcoma cells. NCTD, norcantharidin; mTOR, mammalian target of rapamycin.

The results demonstrated that NCTD could inhibit cell proliferation and induce G2/M cell cycle arrest and apoptosis, which implies that NCTD may be a novel antitumor agent for osteosarcoma treatment.

In the current study, two osteosarcoma cell lines were used to test the antiproliferative effect of NCTD. It was identified that NCTD could inhibit the growth of both osteosarcoma cell lines in a dose- and time-dependent manner. The effect of NCTD on human fibroblasts was also evaluated. Interestingly, human fibroblasts exhibited resistance to NCTD and the $\mathrm{IC}_{50}$ value for $24 \mathrm{~h}$ was $58.82 \mu \mathrm{M}$ (data not shown). Cell cycle imbalance is an essential mechanism involved in the proliferation of malignant tumor cells (14-16). Certain studies have supported the hypothesis that the induction of cell cycle arrest may be an effective method for controlling tumor proliferation (17-19). The current results demonstrated that NCTD induced G2/M cell cycle arrest in both osteosarcoma cell lines in a dose-dependent manner. Similar results have indicated that NCTD is an inhibitor of cell cycle progression in human urinary bladder carcinoma (20) and cervical carcinoma (21). The current results indicated that NCTD could inhibit cell proliferation by inducing $\mathrm{G} 2 / \mathrm{M}$ cell cycle arrest.

Apoptosis, a self-destructive process counteracting tumor growth, is characterized by specific morphological and molecular protein changes in dying cells, including cell membrane blebbing, nuclear condensation and apoptotic body formation (22-24). There are two major pathways involved in the regulation of apoptosis: The mitochondria-mediated intrinsic pathway and the caspase-dependent extrinsic pathway (25). In the caspase-dependent extrinsic pathway, caspase- $3,-8$ and -9 are activated, which subsequently leads to the cleavage of PARP (26). The current results demonstrated that NCTD induced cell shrinkage, nuclear fragmentation and chromatin condensation in osteosarcoma cells. Ultimately, NCTD led to the upregulation of cleaved caspase- 3 and an increase in the downstream target cleaved PARP, which suggested that the extrinsic pathway may also be involved in NCTD-induced cell apoptosis.

Previous studies have reported that the Akt/mTOR signaling pathway is involved in multiple biological behaviors of tumors, including growth, metastasis and apoptosis $(27,28)$. Numerous chemotherapeutic agents inhibit tumor cell growth and induce apoptosis by impacting the Akt/mTOR signaling pathway (29). In the current study, the phosphorylation of Akt and mTOR was observed to be inhibited in osteosarcoma cells following treatment with NCTD. Together with the aforementioned results, this observation suggested that NCTD suppresses the Akt/mTOR signaling pathway, an action that may be involved in NCTD-induced growth inhibition and cell apoptosis.

In conclusion, the current study demonstrated for the first time that NCTD could effectively inhibit cell growth and induce cell cycle arrest and apoptosis in osteosarcoma cells. The current research indicates that NCTD inhibits the Akt/mTOR signaling pathway, an action that may be associated with NCTD-induced growth inhibition and cell apoptosis (Fig. 5). These findings suggest that NCTD may be used for the treatment of patients with osteosarcoma in the future.

\section{Acknowledgements}

Not applicable.

\section{Funding}

No funding was received.

\section{Availability of data and materials}

The datasets used and/or analyzed during the current study are available from the corresponding author on reasonable request.

\section{Authors' contributions}

ZJ and XJ designed the experiment. ZW and YM performed the experiment. YZ analyzed the data and wrote the manuscript.

\section{Ethics approval and consent to participate}

Not applicable.

\section{Patient consent for publication}

Not applicable.

\section{Competing interests}

The authors declare that they have no competing interests.

\section{References}

1. Sergi C and Zwerschke W: Osteogenic sarcoma (osteosarcoma) in the elderly: Tumor delineation and predisposing conditions. Exp Gerontol 43: 1039-1043, 2008.

2. Denduluri SK, Wang Z, Yan Z, Wang J, Wei Q, Mohammed MK Haydon RC, Luu HH and He TC: Molecular pathogenesis and therapeutic strategies of human osteosarcoma. J Biomed Res 30: 5-18. 2016.

3. Pruksakorn D, Phanphaisarn A, Pongnikorn D, Daoprasert K, Teeyakasem P, Chaiyawat P, Katruang N and Settakorn J: AgeStandardized incidence rates and survival of osteosarcoma in northern thailand. Asian Pac J Cancer Prev 17: 3455-3458, 2016. 
4. Mirabello L, Troisi RJ and Savage SA: Osteosarcoma incidence and survival rates from 1973 to 2004: Data from the surveillance, epidemiology, and end results program. Cancer 115: 1531-1543, 2009.

5. Kok SH, Hong CY, Kuo MY, Lee CH, Lee JJ, Lou IU, Lee MS, Hsiao M and Lin SK: Comparisons of norcantharidin cytotoxic effects on oral cancer cells and normal buccal keratinocytes. Oral Oncol 39: 19-26, 2003.

6. Peng F, Wei YQ, Tian L, Yang L, Zhao X, Lu Y, Mao YQ, Kan B, Lei S, Wang GS, et al: Induction of apoptosis by norcantharidin in human colorectal carcinoma cell lines: Involvement of the CD95 receptor/ligand. J Cancer Res Clin Oncol 128: 223-230, 2002.

7. Yang PY, Chen MF, Tsai CH, Hu DN, Chang FR and Wu YC: Involvement of caspase and MAPK activities in norcantharidin-induced colorectal cancer cell apoptosis. Toxicol In Vitro 24: 766-775, 2010

8. Fan YZ, Zhao ZM, Fu JY, Chen CQ and Sun W: Norcantharidin inhibits growth of human gallbladder carcinoma xenografted tumors in nude mice by inducing apoptosis and blocking the cell cycle in vivo. Hepatobiliary Pancreat Dis Int 9: 414-422, 2010.

9. Fulda S: Synthetic lethality by co-targeting mitochondrial apoptosis and PI3K/Akt/mTOR signaling. Mitochondrion 19A: 85-87, 2014.

10. Wang G, Zhang T, Sun W, Wang H, Yin F, Wang Z, Zuo D, Sun M, Zhou Z, Lin B, et al: Arsenic sulfide induces apoptosis and autophagy through the activation of ROS/JNK and suppression of Akt/mTOR signaling pathways in osteosarcoma. Free Radic Biol Med 106: 24-37, 2017.

11. Zhang T, Li S, Li J, Yin F, Hua Y, Wang Z, Lin B, Wang H, Zou D, Zhou Z, et al: Natural product pectolinarigenin inhibits osteosarcoma growth and metastasis via SHP-1-mediated STAT3 signaling inhibition. Cell Death Dis 7: e2421, 2016.

12. Wang D, Yang C, Wang Z, Yang Y, Li D, Ding X, Xu W and Zheng Q: Norcantharidin combined with Coix seed oil synergistically induces apoptosis and inhibits hepatocellular carcinoma growth by downregulating regulatory $\mathrm{T}$ cells accumulation. Sci Rep 7: 9373, 2017.

13. Han Z, Li B, Wang J, Zhang X, Li Z, Dai L, Cao M and Jiang J: Norcantharidin inhibits SK-N-SH neuroblastoma cell growth by induction of autophagy and apoptosis. Technol Cancer Res Treat 16: 33-44, 2017.

14. Hainaut $P$ and Plymoth A: Targeting the hallmarks of cancer: Towards a rational approach to next-generation cancer therapy. Curr Opin Oncol 25: 50-51, 2013.

15. Mills CC, Kolb EA and Sampson VB: Recent advances of cell-cycle inhibitor therapies for pediatric cancer. Cancer Res 77: 6489-6498, 2017.

16. Terzuoli E, Nannelli G, Frosini M, Giachetti A, Ziche M and Donnini S: Inhibition of cell cycle progression by the hydroxytyrosol-cetuximab combination yields enhanced chemotherapeutic efficacy in colon cancer cells. Oncotarget 8: 83207-83224, 2017.
17. Xu P, Xia X, Yang Z, Tian Y, Di J and Guo M: Silencing of TCTN1 inhibits proliferation, induces cell cycle arrest and apoptosis in human thyroid cancer. Exp Ther Med 14: 3720-3726, 2017.

18. Lee KM, Lee K, Choi YK, Choi YJ, Seo HS and Ko SG: SH003induced G1 phase cell cycle arrest induces apoptosis in HeLa cervical cancer cells. Mol Med Rep 16: 8237-8244, 2017.

19. Zhang L, Yan Y, Jiang Y, Qian J, Jiang L, Hu G, Lu Y and Luo C: Knockdown of SALL4 expression using RNA interference induces cell cycle arrest, enhances early apoptosis, inhibits invasion and increases chemosensitivity to temozolomide in U251 glioma cells. Oncol Lett 14: 4263-4269, 2017.

20. Yu CC, Ko FY, Yu CS, Lin CC, Huang YP, Yang JS, Lin JP and Chung JG: Norcantharidin triggers cell death and DNA damage through S-phase arrest and ROS-modulated apoptotic pathways in TSGH 8301 human urinary bladder carcinoma cells. Int J Oncol 41: 1050-1060, 2012

21. Dong X, Li JC, Jiang YY, Xia MY, Tashiro S and Onodera S and Ikejima T: p38-NF- $\mathrm{B}$-promoted mitochondria-associated apoptosis and G2/M cell cycle arrest in norcantharidin-treated HeLa cells. J Asian Nat Prod Res 14: 1008-1019, 2012.

22. Burgess DJ: Apoptosis: Refined and lethal. Nat Rev Cancer 13: 79, 2013.

23. Tiwari M, Prasad S, Tripathi A, Pandey AN, Ali I, Singh AK, Shrivastav TG and Chaube SK: Apoptosis in mammalian oocytes: A review. Apoptosis 20: 1019-1025, 2015.

24. Xiao Z, Shan J, Li C, Luo L, Lu J, Li S, Long D and Li Y: Mechanisms of cyclosporine-induced renal cell apoptosis: A systematic review. Am J Nephrol 37: 30-40, 2013.

25. Elmore S: Apoptosis: A review of programmed cell death. Toxicol Pathol 35: 495-516, 2007.

26. Lopez-Beltran A, Maclennan GT, de la Haba-Rodriguez J, Montironi $\mathrm{R}$ and Cheng L: Research advances in apoptosis-mediated cancer therapy: A review. Anal Quant Cytol Histol 29: 71-78, 2007.

27. Daneshmanesh AH, Hojjat-Farsangi M, Moshfegh A, Khan AS, Mikaelsson E, Österborg A and Mellstedt H: The $\mathrm{PI} 3 \mathrm{~K} / \mathrm{AKT} / \mathrm{mTOR}$ pathway is involved in direct apoptosis of CLL cells induced by ROR1 monoclonal antibodies. $\mathrm{Br}$ J Haematol 169: 455-458, 2015.

28. Yu W, Sun H, Zha W, Cui W, Xu L, Min Q and Wu J: Apigenin attenuates adriamycin-induced cardiomyocyte apoptosis via the PI3K/AKT/mTOR pathway. Evid Based Complement Alternat Med 2017: 2590676, 2017.

29. So KS, Rho JK, Choi YJ, Kim SY, Choi CM, Chun YJ and Lee JC: AKT/mTOR down-regulation by CX-4945, a CK2 inhibitor, promotes apoptosis in chemorefractory non-small cell lung cancer cells. Anticancer Res 35: 1537-1542, 2015. 